See discussions, stats, and author profiles for this publication at: https://www.researchgate.net/publication/322593956

\title{
Espaços e tempos em Geografia: homenagem a António Gama
}

Book · December 2017

DOI: 10.14195/978-989-26-1343-7

CITATIONS

0

4 authors:

Fernanda Cravidão

IMAR Marine and Environmental Research Cen...

46 PUBLICATIONS 29 CitATIONS

SEE PROFILE

Paula Santana

University of Coimbra

247 PUBLICATIONS $\quad \mathbf{2 , 6 2 1}$ CITATIONS

SEE PROFILE
Lúcio Cunha

University of Coimbra

246 PUBLICATIONS 398 CITATIONS

SEE PROFILE

Norberto Santos

University of Coimbra

138 PUBLICATIONS 93 CITATIONS

SEE PROFILE

Some of the authors of this publication are also working on these related projects:

(PALÆEOCOA - PTDC/EPH-ARQ/0326/2014) Neanderthal to Anatomically Modern Human transition in the Côa Valley: Environments, Symbolism and Social networks View project

SMAILE. Study on Mental health - Assessment of the Impact of Local and Economic conditioners View project 


\section{FERNANDA CRAVIDÃO}

\section{IÚCIO CUNHA}

PAULA SANTANA

\section{NORBERTOSANTOS}

(ORG.)

\section{ESPAÇOS E TEMPOS EM GEOGRAFIA}

HOMENAGEM A ANTÓNIO GAMA

IMPRENISA DÁ UNIVERSIDADE DE COIMBRA COIMBRA UNIVERSITY PRESS

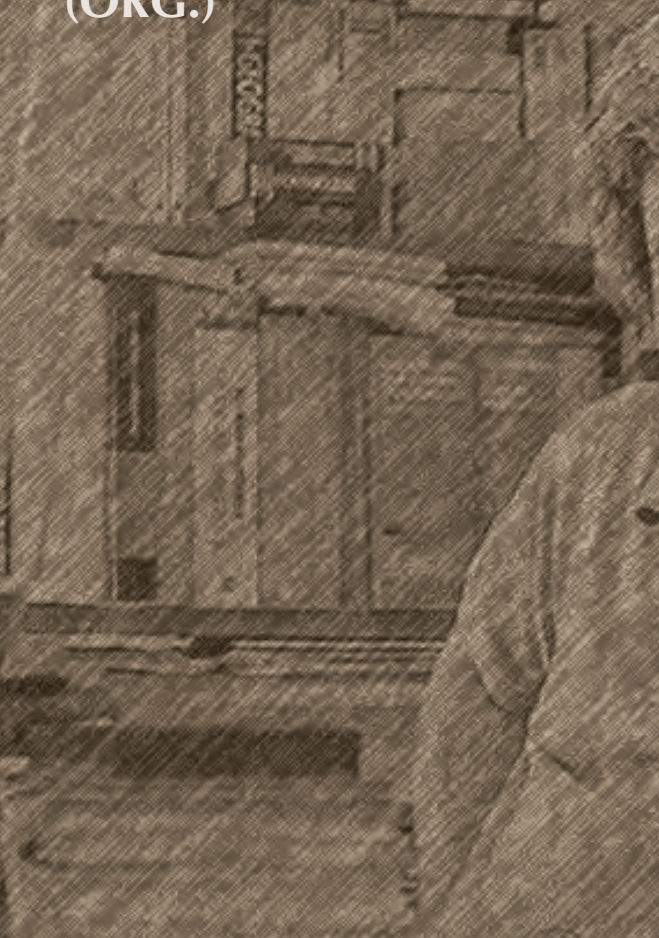


António Gama Mendes, geógrafo, brilhante professor e investigador, faleceu prematuramente em Dezembro de 2014. A sua competência científica, a sua aptidão pedagógica, a sua vastíssima bagagem cultural e, acima de tudo, uma estatura académica muito assente na sua qualidade intelectual e numa imensa generosidade do ponto de vista humano, fizeram com que a Universidade Portuguesa e, particularmente, a Geografia tenham sofrido um forte abalo com a sua partida.

Para além de deixar uma obra significativa em diferentes domínios da Geografia Social, da Geografia Política e da Geografia Cultural, deixou muitos amigos em Portugal e no estrangeiro, em diferentes áreas disciplinares que vão da Geografia à Economia e da Sociologia à Filosofia e à Literatura. Por isso, este livro, com que alguns dos seus amigos de diferentes áreas científicas pretendem homenageá-lo, revisitando alguns dos temas de investigação que Ihe eram mais queridos, de modo a perpetuar a memória de um nome, de uma obra e de uma personalidade absolutamente ímpares na Universidade e na ciência portuguesas. 


\section{Ge $\mathbb{R}$ grafias}

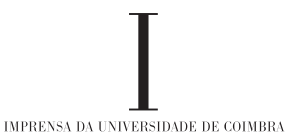




\section{EDIÇÃo}

Imprensa da Universidade de Coimbra

Email: imprensa@uc.pt

URL: http//www.uc.pt/imprensa_uc

Vendas online: http://livrariadaimprensa.uc.pt

\section{ESTRUTURA EDITORIAL}

Fernanda Cravidão

Lúcio Cunha

Paula Santana

Norberto Santos

\section{COORDENAÇÃO EDITORIAL}

Imprensa da Universidade de Coimbra

\section{CONCEÇÃO GRÁFICA}

Imprensa da Universidade de Coimbra

\section{REVISÃO}

Graça Pericão

\section{IMAGEM DA CAPA}

copyright Luísa Ferreira

\section{PRÉ-IMPRESSÃO}

Mickael Silva

\section{EXECUÇÃO GRÁFICA}

www.artipol.net

ISBN

978-989-26-1348-2

ISBN DIGITAL

978-989-26-1343-7

\section{DOI}

https://doi.org/10.14195/978-989-26-1343-7 
FERNANDA CRAVIDÃO

IMPRENSA DA

LÚCIO CUNHA

PAULA SANTANA

NORBERTO SANTOS

UNIVERSIDADE

DE COIMBRA

COIMBRA

UNIVERSITY

PRESS

(COORD.)

\section{ESPAÇOS E TEMPOS \\ EM GEOGRAFIA}

HOMENAGEM A

ANTÓNIO GAMA 
(Página deixada propositadamente em branco) 


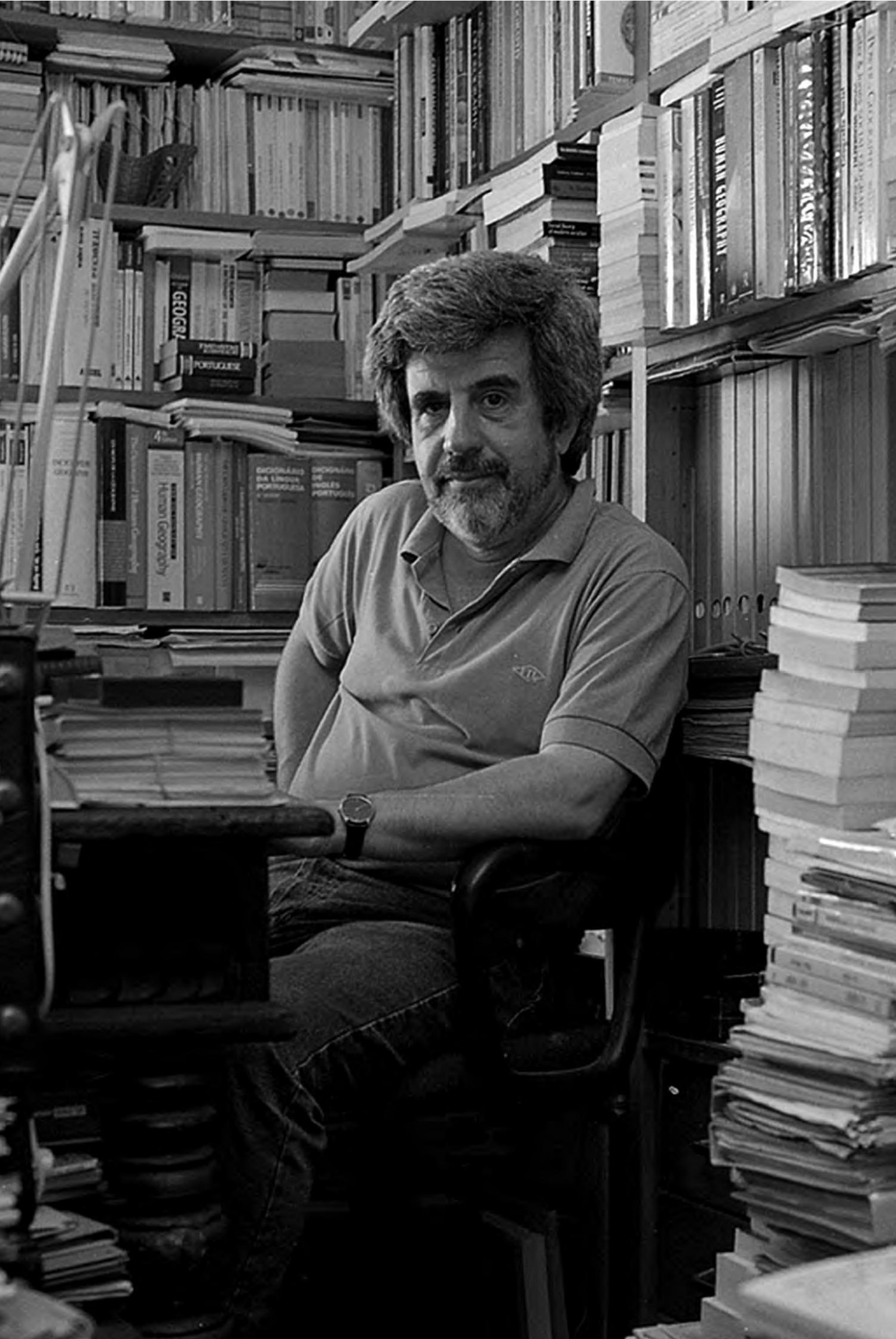


(Página deixada propositadamente em branco) 


\section{SUMÁRIO}

\section{PARTe I}

Ao António Gama Mendes. Os juvenis anos liceais.

Jorge M. R. F. Carvalho

A Biblioteca. O território da felicidade de António Gama. José Reis

Los encuentros geográficos, una oportunidad de compartir algo más que Geografía

Julio Villar Castro e José Luis Alonso Santos

O geógrafo e o seu labirinto: António Gama, uma Geografia Vivida Rui Jacinto

António Gama, um apaixonado pela Geografia e pelas mini rosas. Maria Adélia de Souza

As travessias bertrandianas à construção da geografia física Messias Modesto dos Passos

Problemas de ontem e de hoje que poderia voltar a discutir com o nosso amigo António Gama se... Júlio Marques Mota

Revisitando o artigo "Análise espacial de uma transformação agrícola”. 115 Iva Pires, Graça Rolo e Francisco Henriques 


\section{PARTe II}

Contributo para uma Geomorfologia Cultural do Maciço de Sicó

Lúcio Cunha

Fosso do médio Zêzere. Um livro aberto de geomorfologia

Luciano Lourenço

A paisagem como elemento de sustentabilidade nos territórios de fronteira.

O exemplo do município do Sabugal ....

Adélia Nunes e António Campar de Almeida

Tempo e espaço num geossistema cársico: os "pilares" em que assenta e se sustenta

a interpretação da sua evolução geológico-geomorfológica.....

Luca Antonio Dimuccio

\section{PARTE III}

Nichos de nuevas y renovadas actividades en espacios y lugares centrales de la Raya ibérica....

Lorenzo López Trigal

Brozas, villa cacereña de frontera

Antonio-José Campesino Fernández

Antropoceno, cidades e geografia

João Ferrão

A Geografia portuguesa em 1929 na correspondência entre Amorim Girão

e Gonzalo de Reparaz Ruiz

João Carlos Garcia e Enric Mendizàbal Riera

A Geografia em Alberto Sampaio - desde as explorações geográficas pela

biblioteca do historiador vimaranense

Miguel Sopas de Melo Bandeira

O papel dos baldios na revitalização das comunidades rurais

Pedro Hespanha 
Novas dinâmicas dos territórios rurais: a participação local, o reforço

e democratização do Estado e da gestão pública.

Maria Adosinda de Almeida Henriques

Morfogénese e intençóes, planos e projetos de atravessamento da Baixa

de Coimbra: outros contributos de um geógrafo....

Mário Gonçalves Fernandes

Equidade em saúde. O papel das condições socioeconómicas e dos cuidados de saúde primários

Paula Santana e Pedro Lopes Ferreira

A escola em territórios de baixa densidade. Proposta para a construção de uma matriz de reorganização da rede escolar.

A. M. Rochette Cordeiro

Desconstruçóes reconstruídas sobre o processo de envelhecimento. Perspetivas geográficas em territórios literários

Fátima Velez de Castro

Apontamentos históricos sobre a Mui Nobre Vila de Álvaro. Contributo para a sua redescoberta

Anselmo Casimiro Ramos Gonçalves e Luis Alexandre Mendes

A Velha e a Nova Luz: dinâmicas geográficas de um processo

de des-reterritorialização

Ana Maria Cortez Vaz

Revisitar o itinerário raiano do Prof. Gama Mendes através

de uma visão geográfica

Emanuel de Castro e Ana Lopes

\section{PARTE IV}

Tempos e espaços de lazer numa perspectiva de integração social: questôes de base geográfica.

Patrícia Rego, Sara Pedro-Rego, Pascale Millecamps, Fernanda Pereira,

Rita Silva e Luis Sá-Fernandes 
O turismo, o turista e o território - uma nova centralidade para a geografia? Fernanda Cravidão e Paulo Nossa

Gastronomia e vinhos. Um produto sempre novo com raízes nas tradiçôes da cultura da população portuguesa Norberto Santos

Turismo e fronteiras: uma relação dinâmica entre o turismo cultural e político....... João Luís Jesus Fernandes

Património e turismo literário: Leiria queiroziana...... Sara Fernandes e Paulo Carvalho

Turismo, lazer e património natural no destino Madeira Claudete Oliveira Moreira e Albano Figueiredo

Turismo: um espelho da(s) realidade(s) contemporânea(s) - do mundo globalizado à globalização do medo e da insegurança Mónica Morais de Brito

Turismo e cinema: uma outra abordagem através do filme de animação Astérix - O Dominio dos Deuses. Jorge Humberto Soares Marques

O turismo, recreio e lazer na sociedade de consumo Carlos Costa

O elétrico e o turismo - o caso da cidade de Coimbra Paulo Simóes

Dinâmica das relaçóes entre espaços, turismo e religiosidade em Coimbra 701 Ana Paula Pinto Bastos

\section{Parte V}

Acerca do Congresso da Oposição Democrática de Aveiro de 1973 Luis Reis Torgal

Conhecimento, afetividade e cuidado nos processos educativos em sociedades multiculturais

João Maria André 
Uma leitura analítica do manuscrito clássico de Karl Marx

\section{Edna Maria Furtado}

A classe média à deriva

\section{Elísio Estanque}

Breve reflexão sobre a importância da Investigação Operacional no estudo

de Avaliação Estratégica de Impacto Ambiental dedicado à localização

do novo aeroporto de Lisboa

João Clímaco e José Craveirinha

Para uma teoria metafísica da civilização africana

José Luis Pires Laranjeira 